\title{
Association between ozone exposure and prevalence of mumps: a time-series study in a Megacity of Southwest China
}

\author{
Wenjun Xie ${ }^{1} \cdot$ Han Zhao ${ }^{2} \cdot$ Chang Shu ${ }^{3} \cdot$ Bin Wang ${ }^{1,4} \cdot$ Wen Zeng $^{5} \cdot$ Yu Zhan ${ }^{1,4}$ (D) \\ Received: 26 April 2021 / Accepted: 13 July 2021 / Published online: 27 July 2021 \\ (C) The Author(s), under exclusive licence to Springer-Verlag GmbH Germany, part of Springer Nature 2021
}

\begin{abstract}
In the present study, we aim to evaluate the delayed and cumulative effect of ozone $\left(\mathrm{O}_{3}\right)$ exposure on mumps in a megacity with high population density and high humidity. We took Chongqing, a megacity in Southwest China, as the research area and 20132017 as the research period. A total of 49,258 confirmed mumps cases were collected from 122 hospitals of Chongqing. We employed the distributed lag nonlinear models with quasi-Poisson link to investigate the relationship between prevalence of mumps and $\mathrm{O}_{3}$ exposure after adjusting for the effects of meteorological conditions. The results show that the effect of $\mathrm{O}_{3}$ exposure on mumps was mainly manifested in the lag of 0-7 days. The single-day ;lag effect was the most obvious on the 4th day, with the relative risk (RR) of mumps occurs of 1.006 (95\% CI: $1.003-1.007)$ per $10 \mu \mathrm{g} / \mathrm{m}^{3}$ in the $\mathrm{O}_{3}$ exposure. The cumulative $\mathrm{RR}$ within 7 days was 1.025 (95\% CI: 1.013-1.038). Our results suggest that $\mathrm{O}_{3}$ exposure can increase the risk of mumps infection, which fills the gap of relevant research in mountainous areas with high population density and high humidity.
\end{abstract}

Keywords Mumps $\cdot$ Air pollution $\cdot$ Distributed lag $\cdot \mathrm{O}_{3} \cdot$ Cumulative exposure

\section{Introduction}

Respiratory diseases such as coronavirus (COVID-19) have been the hotspot of public health concern. Mumps caused by

Responsible Editor: Lotfi Aleya

Wen Zeng

zengwen@stu.scu.edu.cn

Yu Zhan

yzhan@scu.edu.cn

1 Department of Environmental Science and Engineering, Sichuan University, Chengdu, Sichuan, China

2 Chongqing Center for Disease Control and Prevention, Chongqing, China

3 Ministry of Education Key Laboratory of Child Development and Disorders; National Clinical Research Center for Child Health and Disorders, Children's Hospital of Chongqing Medical University, Chongqing, China

4 Yibin Institute of Industrial Technology, Sichuan University Yibin Park, Yibin, China

5 Sichuan University-the Hong Kong Polytechnic University Institute for Disaster Management and Reconstruction, Chengdu, Sichuan, China the mumps virus $(\mathrm{MuV})$ is one of the serious respiratory infections (Hviid et al. 2008). Patients often have symptoms such as parotid gland swelling and pain, which may lead to encephalitis, meningitis, orchitis, and other complications in severe cases (Betakova et al. 2013; Rubin et al. 2016). The number of mumps in China declined from 2013 to 2016 but rebounded from 2017 to 2018, which might be associated with the change in air quality (WHO 2020; Zhang et al. 2021). For example, urban $\mathrm{O}_{3}$ pollution gradually increased from 2015 to 2017 in China (Guo et al. 2020). $\mathrm{O}_{3}$ is harmful to human health, and short-term exposure to $\mathrm{O}_{3}$ may increase morbidity, hospitalization, and mortality of cardiovascular and respiratory diseases (Yan et al. 2013). It is thus important to study the relationship between mumps and air quality for disease prevention.

The previous epidemiological studies have shown that air pollution would enhance the health risk from respiratory infections (Thurston et al. 2017). According to a report from the World Health Organization (WHO), acute pollution incidents in a number of cities around the world have led to an increase in morbidity and mortality (WHO 2016). The animal toxicology studies have shown that $\mathrm{O}_{3}$ exposure can cause antioxidant depletion in mice and oxidation of lipids and proteins in respiratory tract lining fluid (RTLF), which would exacerbate 
respiratory infections (Valacchi et al. 2004). However, the existing results on the association between the outbreak of mumps and environmental factors varied widely (Ho et al. 2015; $\mathrm{Hu}$ et al. 2018; Li et al. 2017). A study reported that the levels of sulfur dioxide $\left(\mathrm{SO}_{2}\right)$ and nitrogen dioxide $\left(\mathrm{NO}_{2}\right)$ were significantly associated with the prevalence of mumps at 2-day lag, but 23-day lag for $\mathrm{SO}_{2}, \mathrm{O}_{3}$, and respirable particulate matter $\left(\mathrm{PM}_{10}\right)$ (Hao et al. 2019). It is worth noting that these studies were all from plains and coastal areas, and more efforts are needed to evaluate the relationship in other geographical regions such as mountainous areas.

In environmental epidemiological analyzes, time-series regression models are widely used to quantify the effects of air pollution exposures (Bhaskaran et al. 2013; Modarres and Dehkordi 2005; Young and Minchin 1991). On the basis of the empirical exposure-response relationships, the relative risks of human health attributable to air pollution exposure were quantitatively evaluated (Onozuka and Hashizume 2011). In light of the advancement of epidemiological research methods, researchers have found that the effects of air pollution on human health tend to be hysteretic and/or nonlinear (Luo et al. 2018). In the distributed lag non-linear model (DLNM), the cross-basis functions of independent variables are constructed to evaluate the exposure-lag-effect relationship by accounting for the hysteresis and non-linear relationships (Gasparrini et al. 2010).

The purpose of this study is to evaluate the relationship between $\mathrm{O}_{3}$ exposure and the prevalence of mumps. We selected Chongqing as the study area, which is a typical mountainous city located in Southwest China and the upper reaches of the Yangtze River. Chongqing covers an area of 82,400 $\mathrm{km}^{2}$ with a permanent population of approximately 31 million (NBSC 2019). Compared to the areas selected in the previous studies on mumps, Chongqing is a mountainous, humid, and densely populated area. We combined DLNM and the generalized additive model (GAM) to explore the exposure-lageffect relationship and evaluate the relative risk (RR) (Gasparrini et al. 2010; Luo et al. 2018). The results from this study are expected to advance the understanding of the adverse effects of air pollution on mumps and to provide a basis for early warning with potential medical intervention.

\section{Materials and methods}

\section{Study area}

Chongqing $\left(28^{\circ} 10^{\prime} \sim 32^{\circ} 13^{\prime}\right.$ North, $105^{\circ} 11^{\prime} \sim 110^{\circ} 11^{\prime}$ East; Fig. 1 ) is a megacity of Southwest China. It has a humid subtropical monsoon climate. It's a typical mountainous, high-humidity, and high-population-density area, with annual average relative humidity $(\mathrm{RH})$ of $75.1 \%$ and average temperature of $16.8^{\circ} \mathrm{C}$ during 2013-2017 (CMA 2020).

\section{Data collection}

A collection of daily diagnosed mumps cases was reported from 122 hospitals in Chongqing from January 1, 2013 to December 31, 2017. According to International Classification of Diseases, the 10th Revision (ICD-10),

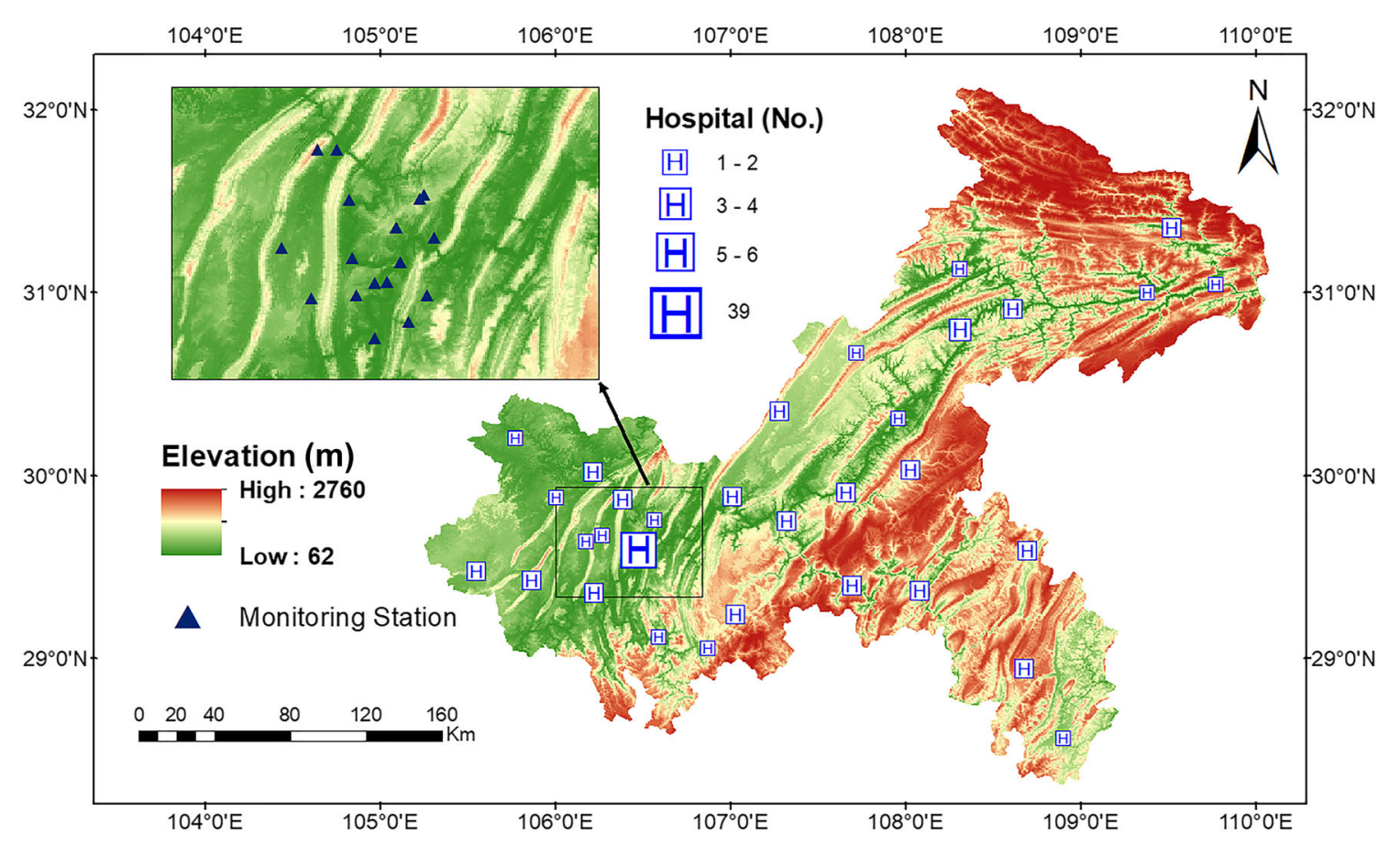

Fig. 1 Locations of air pollutants monitoring stations and hospitals in Chongqing 
mumps is coded as B26. A total of 49,258 confirmed cases who lived in the study area were included. The daily concentrations of $\mathrm{O}_{3}, \mathrm{SO}_{2}, \mathrm{NO}_{2}$, carbon monoxide (CO), fine particulate matter $\left(\mathrm{PM}_{2.5}\right)$, and $\mathrm{PM}_{10}$ during 2013-2017 were monitored at 17 air quality stations in Chongqing, which were maintained by the Ministry of Ecology and Environment of China (MEEC 2020). The daily meteorological conditions, including relative humidity, precipitation, temperature, sunshine duration, atmospheric pressure, wind speed, and evaporation, were observed at 12 meteorological stations maintained by the China Meteorological Administration (CMA 2020). The daily concentrations of the air pollutants were calculated from the hourly concentrations. We excluded the days with $>25 \%$ missing data of hourly concentrations (4 days during the study period), and then employed an iterative imputation method named missForest (Stekhoven and Buehlmann 2012) to fill the missing values.

\section{Statistical analyzes}

In this study, the DLNM was mainly employed to evaluate the association between $\mathrm{O}_{3}$ exposure and the prevalence of mumps. We selected GAM as the workhorse model (Zeng et al. 2020) and the quasi-Poisson link as the connection function (Kim et al. 2015). With respect to the lag effects, we first constructed a single-day lag model, which however, might suffer the problem of temporal misalignment (Zhu et al. 2019). As cumulative exposure had a greater impact on human health (Lee et al. 2019; Samoli et al. 2013), we calculated the effect between cumulative $\mathrm{O}_{3}$ exposure and the risk of mumps based on the single-day lag model. Considering the potential impact of meteorological factors on the prevalence of mumps, we modeled the meteorological factors as confounding variables with natural cubic spline functions. As the outbreak of mumps has a certain seasonal regularity, the indicator variable of month is added to the model (Qiu et al. 2019). The model is as follows:

$$
\begin{aligned}
& Y_{t}=\mathrm{P}\left(\mu_{\mathrm{t}}\right) \\
& \mathrm{E}\left(Y_{t}\right)=\mu_{\mathrm{t}} \\
& \begin{aligned}
\log \left(\mu_{\mathrm{t}}\right)= & \alpha+\beta C_{x, l}+\sum \mathrm{s}(\text { Meteorological factor }) \\
& \quad+\mathrm{ns}(\text { Time }, 5 * 7)+\mathrm{f}(M)
\end{aligned}
\end{aligned}
$$

where $Y_{t}$ is the number of mumps caused by exposure to air pollutants on day $\mathrm{t} ; \mu_{t}$ is the average of $Y_{t} ; \alpha$ is the intercept; $C_{x, l}$ is the cross-basic function of exposure to $\mathrm{O}_{3}$ for $l$ day; $\beta$ is the regression coefficient; $s()$ is natural cubic spline function; Meteorological factors include relative humidity, precipitation, temperature, sunshine hours, air pressure, wind speed, and evaporation; Time is a time series; $M$ is a monthly variable. The degrees of freedom (df) of meteorological factors are determined by the Quasi-Poisson Information Criterion (Q-
AIC). We set the degrees of freedom to 7 per year for Time in order to address the long-term trend and seasonal fluctuation (Peng et al. 2006).

Considering the strong seasonality of mump outbreaks, we conducted subgroup analyses of season to evaluate the seasonspecific effects of $\mathrm{O}_{3}$ exposure on mumps. A year was divided into a warm season (April to September) and a cool season (October to March).

Moreover, we developed two-pollutant models and performed subgroup analyzes to explore the potentially superimposing or synergistic effects of $\mathrm{O}_{3}$ and other air pollutants, including $\mathrm{SO}_{2}, \mathrm{NO}_{2}, \mathrm{PM}_{2.5}$, and $\mathrm{PM}_{10}$. The formula of the two-pollutant model is as follows:

$$
\begin{aligned}
\log \left(\mu_{\mathrm{t}}\right)= & \alpha+\beta C_{x, l}+\gamma C_{y, l} \\
& +\sum \mathrm{s}(\text { Meteorological factor }) \\
& +\mathrm{ns}(\text { Time }, 5 * 7)+\mathrm{f}(M)
\end{aligned}
$$

where $C_{y, l}$ represents the cross-basis function of exposure to the second pollutant $y$ (i.e., $\mathrm{SO}_{2}, \mathrm{NO}_{2}, \mathrm{PM}_{2.5}$, or $\mathrm{PM}_{10}$ ) and its lag $e$ effects; $\gamma$ is vector of coefficients; and please refer to Eq. (3) for the meanings of the other variables. For the subgroup analyzes, we divided the whole dataset into three groups (i.e., low, moderate, and high) according to the $1 / 3$ and $2 / 3$ quantiles of a second pollutant concentrations. For each group, we developed a separate DLNM model based on Eq. (3). The estimated RR for each group was then comparatively evaluated to examine potentially synergistic effect.

After obtaining the estimates of each regression coefficients $\mathrm{K}$ (e.g., $\beta, \gamma$ ), we then calculate the relative risks (RR) as follows:

$R R=e^{\mathrm{K} * \mathrm{C}}$

where $C$ represents the increase of air pollution exposure (set to $10 \mu \mathrm{g} / \mathrm{m}^{3}$ in the present study), the effects of air pollution exposure on mumps is expressed as RR with $95 \%$ confidence interval $(95 \% \mathrm{CI})$. We then compared the RR under different conditions to illustrate the impact of $\mathrm{O}_{3}$ on mumps and explored the potential synergistic effects between $\mathrm{O}_{3}$ and other pollutants.

Moreover, we conducted sensitivity analyzes to evaluate the robustness of the modeling results. We first changed the number of lag-days of cross-basis function (5-30 days) to estimate the maximum lag days. We then changed the degrees of freedom of the time-series and temperature to smooth the effect of long-term trend. Finally, we randomly sampled 15\% of the data to establish a validation data set, with the remaining $85 \%$ of the data for building the model.

All our analyzes were performed using R (version 4.0.2) with packages "dlnm" (Gasparrini 2011), "splines" (R Development Core ;Team 2012), and "mgcv" (Wood 2011). 
Table 1 Description of air pollution and meteorological factors in Chongqing, 2013-2017

\begin{tabular}{|c|c|c|c|c|c|c|c|}
\hline \multirow[t]{2}{*}{ Variables ${ }^{a}$} & \multirow[t]{2}{*}{ Mean } & \multirow[t]{2}{*}{$\mathrm{SD}^{\mathrm{b}}$} & \multirow[t]{2}{*}{ Min } & \multicolumn{3}{|c|}{ Percentiles } & \multirow[t]{2}{*}{ Max } \\
\hline & & & & $25 \%$ & $50 \%$ & $75 \%$ & \\
\hline $\mathrm{NO}_{2}\left(\mu \mathrm{g} / \mathrm{m}^{3}\right)$ & 41.4 & 12.2 & 13.1 & 32.6 & 40.0 & 48.6 & 91.9 \\
\hline $\mathrm{SO}_{2}\left(\mu \mathrm{g} / \mathrm{m}^{3}\right)$ & 19.2 & 12.2 & 4.1 & 11.0 & 15.3 & 23.6 & 78.3 \\
\hline $\mathrm{O}_{3}\left(\mu \mathrm{g} / \mathrm{m}^{3}\right)$ & 41.5 & 28.5 & 3.1 & 18.5 & 36.1 & 57.9 & 216.5 \\
\hline $\mathrm{PM}_{2.5}\left(\mu \mathrm{g} / \mathrm{m}^{3}\right)$ & 55.9 & 34.6 & 7.5 & 31.9 & 45.6 & 69.1 & 214.5 \\
\hline $\mathrm{PM}_{10}\left(\mu \mathrm{g} / \mathrm{m}^{3}\right)$ & 86.5 & 47.5 & 13.0 & 53.2 & 74.7 & 106.0 & 296.6 \\
\hline $\mathrm{CO}\left(\mathrm{mg} / \mathrm{m}^{3}\right)$ & 1.0 & 0.3 & 0.3 & 0.8 & 1.0 & 1.2 & 2.8 \\
\hline Temperature $\left({ }^{\circ} \mathrm{C}\right)$ & 16.8 & 7.5 & -0.4 & 10.0 & 17.3 & 22.8 & 32.0 \\
\hline Humidity (\%) & 75.1 & 9.5 & 41.3 & 68.7 & 75.0 & 82.0 & 98.0 \\
\hline Precipitation (mm) & 3.2 & 7.5 & 0.0 & 0.0 & 0.2 & 2.7 & 65.5 \\
\hline Wind speed $(\mathrm{m} / \mathrm{s})$ & 1.8 & 0.5 & 0.3 & 1.4 & 1.8 & 2.1 & 4.2 \\
\hline Evaporation (mm) & 2.3 & 1.4 & 0.1 & 1.2 & 1.8 & 3.1 & 7.2 \\
\hline Pressure $(\mathrm{hPa})$ & 953.6 & 7.8 & 927.1 & 947.5 & 953.3 & 959.8 & 976.6 \\
\hline Sunshine duration (hour) & 3.8 & 3.6 & 0.0 & 0.2 & 2.8 & 6.8 & 11.5 \\
\hline
\end{tabular}

${ }^{\mathrm{a}}$ Daily average; ${ }^{\mathrm{b}}$ Standard deviation

\section{Results and discussion}

\section{Correlational analysis}

The average concentrations of $\mathrm{NO}_{2}, \mathrm{SO}_{2}, \mathrm{O}_{3}, \mathrm{PM}_{2.5}, \mathrm{PM}_{10}$, and $\mathrm{CO}$ were $41.4 \mu \mathrm{g} / \mathrm{m}^{3}, 19.2 \mu \mathrm{g} / \mathrm{m}^{3}, 41.5 \mu \mathrm{g} / \mathrm{m}^{3}, 55.9 \mu \mathrm{g} /$ $\mathrm{m}^{3}, 86.5 \mu \mathrm{g} / \mathrm{m}^{3}$, and $1.0 \mathrm{mg} / \mathrm{m}^{3}$, respectively. The average temperature was $16.8^{\circ} \mathrm{C}$, and the average relative humidity was $75.1 \%$ (Table 1). The spearman correlations between the prevalence of mumps, air pollutants, and meteorological factors are shown in Figure S1. Among them, the prevalence of mumps was significantly positively correlated with $\mathrm{O}_{3}$ and $\mathrm{SO}_{2}$, with correlation coefficients of 0.17 and 0.05 , respectively $(P<0.05)$. While, the prevalence of mumps was significantly negatively correlated with $\mathrm{NO}_{2}, \mathrm{CO}, \mathrm{PM}_{2.5}$, and $\mathrm{PM}_{10}$, with correlation coefficients of $-0.07,-0.16,-0.08$, and -0.03 , respectively $(P<0.05)$.

Figure 2 shows the seasonal fluctuations of mumps cases, daily average $\mathrm{O}_{3}$ concentration and daily average temperature. The daily prevalence of mumps showed a clear seasonality. We observed that the prevalence of mumps was the highest in summer, followed by winter. The $\mathrm{O}_{3}$ concentrations showed a

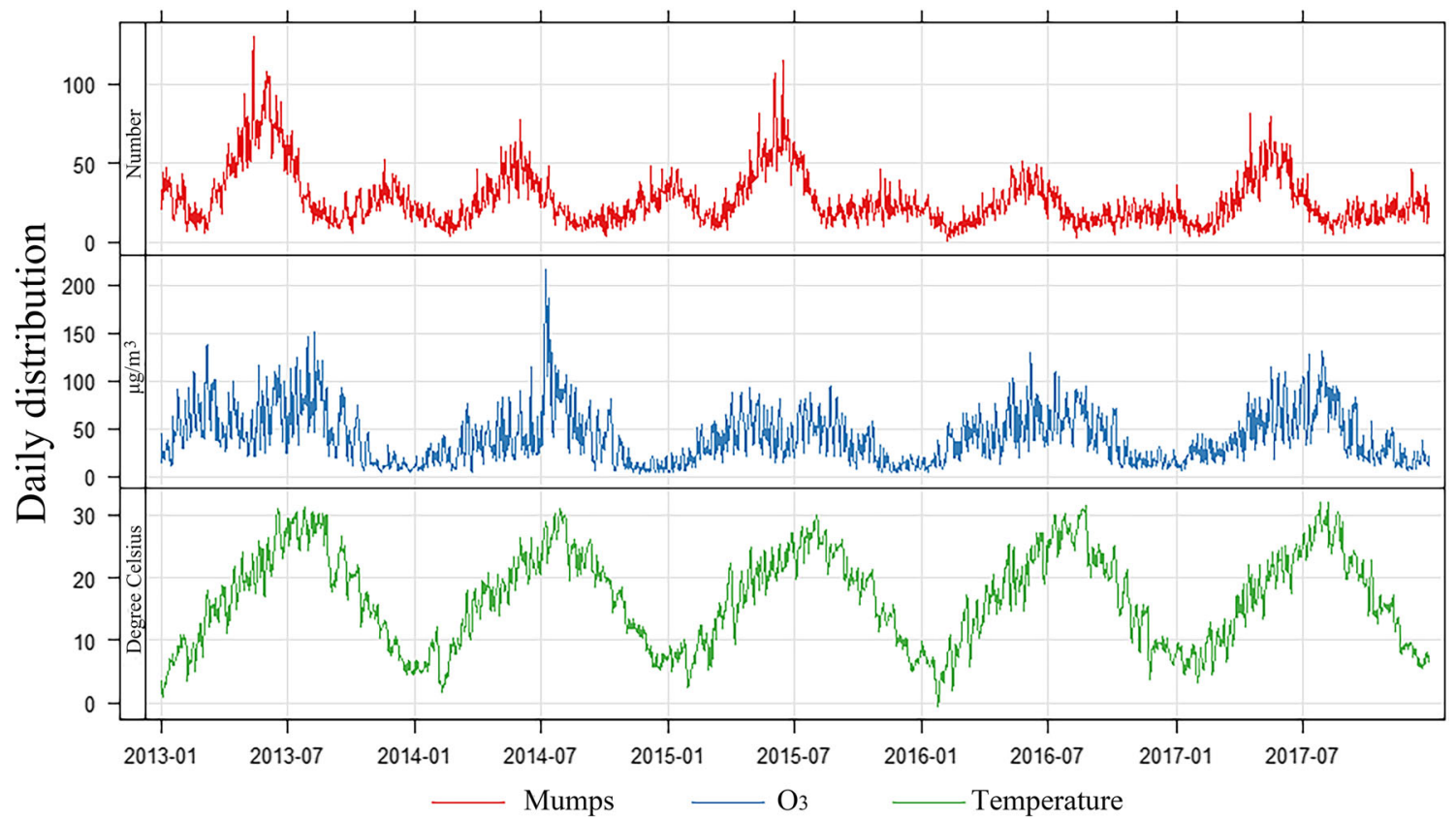

Fig. 2 Time series of mumps cases, $\mathrm{O}_{3}$ concentrations, and air temperature during 2013-2017 
similar temporal pattern, which were the highest in hot seasons. We found a total of 49,258 confirmed cases of mumps during 2013-2017, consisting of 30,860 and 18,398 cases in the warm and cool seasons, respectively. The average number of cases per day was approximately 27. In 535 days of the study period, the number of cases exceeded 30 per day.

During the study period, the high levels of $\mathrm{O}_{3}$ were due to photochemical reactions and elevated concentrations of volatile organic compounds (VOCs) and $\mathrm{NO}_{\mathrm{x}}$ from industrial and transport emissions (Lee et al. 2019; Su et al. 2018). A plenty of previous studies have estimated the association between air pollution and respiratory infectious diseases. A study in South Korea found that the prevalence of tuberculosis was highly correlated with $\mathrm{SO}_{2}$ exposure (Hu et al. 2018), and several studies reported that particulate matters could increase the risk of influenza (Clifford et al. 2015; DeFelice 2020; Feng et al. 2016).

\section{Distributed lag non-linear models (DLNM)}

Figure S2 summarizes the most prominent single-day lag effect of each air pollutant on the prevalence of mumps. Only $\mathrm{O}_{3}$ exhibited significant effects on the prevalence of mumps $(P<0.01)$. Our results are inconsistent with the previous studies with respect to the adverse health effects from exposure to particulate matters. The previous studies on air pollutants and respiratory infectious diseases considered that atmospheric particles could carry viruses and hence aggregated the ability of viruses to infect respiratory tract (Chen et al. 2018; CruzSanchez et al. 2013; Griffin 2007). More efforts such as metaanalyzes are required to investigate the spatiotemporal heterogeneity of the associations.

Among different lags of days, we found that the increase in $\mathrm{O}_{3}$ concentrations was significantly associated with the increased prevalence of mumps during the 7-day lag time window $(P<0.01)$.

The DLNM results show that the lag-effect of $\mathrm{O}_{3}$ exposure on the prevalence of mumps is in a positive and nonlinear manner. The complete lag-curve shows a trend of rising in the first 4 days and then falling thereafter. The exposureresponse effect was not statistically significant on the first day of exposure due to the lag effect. In the time lag of 4 days, the highest effect of the $\mathrm{O}_{3}$ exposure emerged, with the maximum RR of 1.006 (95\% CI: 1.003-1.007). The effect of $\mathrm{O}_{3}$ exposure on the prevalence of mumps gradually decline afterwards and became negligible on the 7 th day, with RR of 1.0001 (95\% CI: 0.997-1.005; Fig. 3).

In the previous study from Wuhan, no significant effect of $\mathrm{O}_{3}$ on the prevalence of mumps was found in the range of 7day lag but a lag of 23 days (Hao et al. 2019). The difference in the lag days than our study might result from the large differences between Wuhan and Chongqing in geographical and climatic conditions, as well as local populations. A plenty

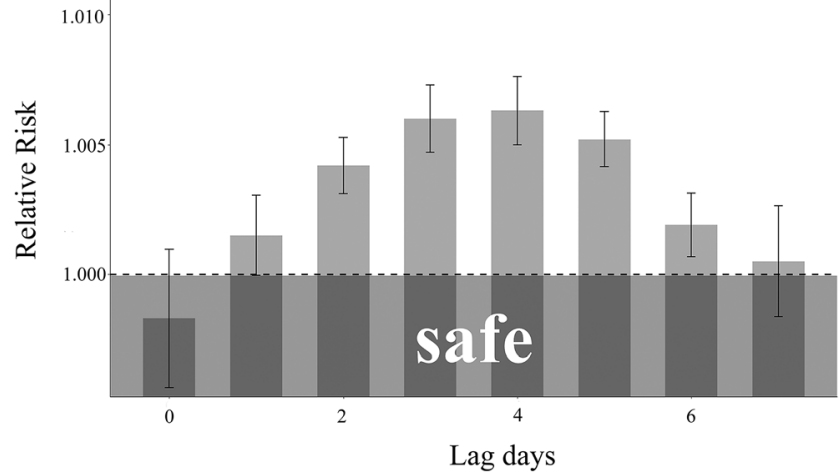

Fig. 3 Estimated relative risk (RR) and 95\% CIs of mumps for a $10 \mu \mathrm{g} /$ $\mathrm{m}^{3}$ increase of $\mathrm{O}_{3}$ at lag- 0 to lag-7 days

of studies found that temperature had an effect on prevalence of mumps (Ho et al. 2015; Onozuka and Hashizume 2011). A recent study from the western China indicated that precipitation and wind speed also had effect on the prevalence of mumps (Zha et al. 2020). Warm and humid weather would promote $\mathrm{MuV}$ reproduction and evolution, enhancing the infection risk (Nenna et al. 2017). More efforts are required to investigate the combination with $\mathrm{MuV}$ transmission mechanism, population immunity model, and more epidemiological evidence.

Considering the accumulated effects of air pollution exposure, we calculated the cumulative effect of $\mathrm{O}_{3}$ exposure on mumps (Fig. 4). We found that the RR for the prevalence of mumps increased rapidly within 1-5 days, which was 1.022 (95\% CI: $1.011-1.032$ ), indicating that $10 \mu \mathrm{g} / \mathrm{m}^{3}$ increase in daily $\mathrm{O}_{3}$ exposure during 5-day lag would lead to the increase in the prevalence of mumps by $2.2 \%$. The cumulative effect caused by the $\mathrm{O}_{3}$ exposure on the 6th to 7 th days would gradually decline, while the growth rate of RR also gradually leveled off. There was no significant association between $\mathrm{O}_{3}$ and the prevalence of mumps after 7-day lag, and the cumulative $\mathrm{RR}$ of $\mathrm{O}_{3}$ short-term exposure within 7 days was 1.025 (95\% CI: $1.013-1.038$ ) for $10 \mu \mathrm{g} / \mathrm{m}^{3}$ increase in the daily $\mathrm{O}_{3}$ concentration.

Figure 5 shows the results of subgroup analyses of season using the single-day-lag models. The effects of $\mathrm{O}_{3}$ exposure on mumps were statistically insignificantly different between the warm and cool seasons, with cumulative RR of 1.034 (95\% CI: 1.015-1.053) and 1.066 (95\% CI: 1.029-1.103), respectively. The RR for each lag-day was insignificantly different between the cool and warm seasons neither. In the warm season, the RR first increased from lag-0 to lag-4 day, and then gradually decreased till lag-7 day. In the cool season, the RR remained steady from lag- 0 to lag- 6 day, followed by an increase till lag-7 day.

It should be noted that mumps outbreak occurred relatively more frequently in the warm season than the cold season (Fig. 2 ), which is consistent with the results of the previous study on mumps in China (Cui et al. 2014). The season-specific effects 
Fig. 4 Cumulative Relative Risk (RR) and $95 \%$ CIs of mumps for a $10 \mu \mathrm{g} / \mathrm{m}^{3}$ increase in $\mathrm{O}_{3}$ exposure

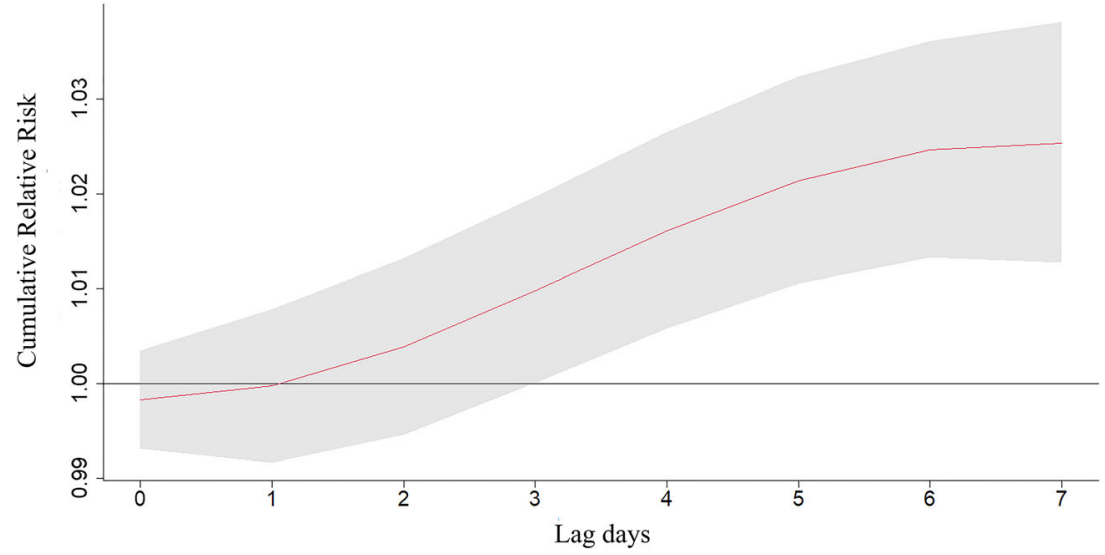

of $\mathrm{O}_{3}$ exposure on mumps were comparable to those reported in the previous studies (Kai et al. 2018; Qing et al. 2020). Although the RR was insignificantly different between these two seasons, more pollens in spring and more infectious diseases in winter might exacerbate the risk of mumps (Qing et al. 2020). In addition, we found that the single-day RR became significant at lag- 6 day in the cool season, compared to lag-2 day in the warm season. Warm conditions are suitable for virus survival and replication, causing people more susceptible to infection (Averett 2016; Hess et al. 2014).

In the results of the single-pollutant models, we found significant association of mumps with $\mathrm{O}_{3}$ exposure, but none for all the other regularly monitored air pollutants (Figure S2). In order to evaluate the synergistic effects between the other pollutants and $\mathrm{O}_{3}$, we developed two-pollutant models and performed subgroup analyzes. Figure 6 shows the cumulative RR calculated by using the single- and two-pollutant models.

After inclusion of a second pollutant, the cumulative RR for $\mathrm{O}_{3}$ did not change significantly. For the subgroup analyzes, while the $\mathrm{RR}$ for $\mathrm{O}_{3}$ was slightly different among the three groups, the highly overlapped confidence intervals represent insignificant difference (Figure S3). Figure S4 shows the single-day RR for a $10 \mu \mathrm{g} / \mathrm{m}^{3}$ increase of a second pollutant (i.e., $\mathrm{PM}_{2.5}, \mathrm{PM}_{10}, \mathrm{SO}_{2}$ and $\mathrm{NO}_{2}$, respectively) in the two-

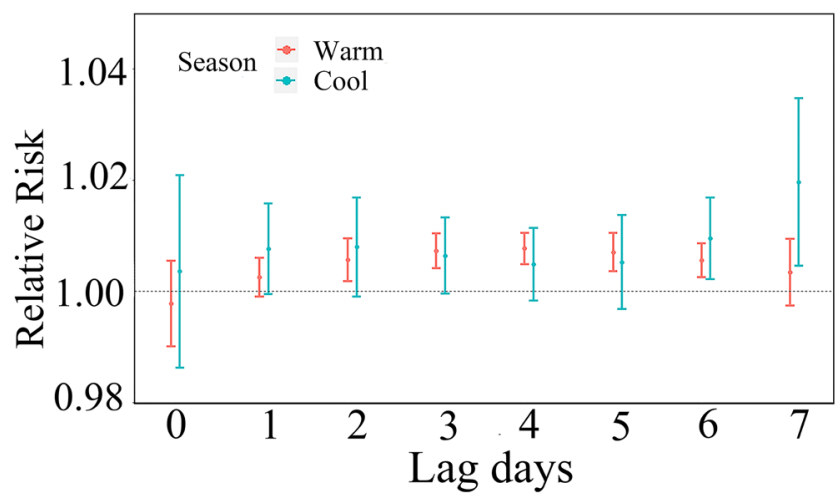

Fig. 5 Estimated relative risk (RR) and 95\% CIs of mumps for a $10 \mu \mathrm{g} /$ $\mathrm{m}^{3}$ increase of $\mathrm{O}_{3}$ at lag-0 to lag-7 days in the warm (April to September) and cool (October to March) seasons pollutants models. The RR for the second pollutant was insignificant or marginally significant through the lag days. The analysis results therefore suggest negligibly synergistic effects between $\mathrm{O}_{3}$ and other pollutants.

Currently, there still lacks research clearly explaining the mechanism of $\mathrm{O}_{3}$ exposure affecting the pathogenesis of mumps. Virus transmissions mainly occur through inhalation of aerosol particles, respiratory droplets, and body contact (Meselson 2020; van Doremalen et al. 2020). People under enhanced oxidative stress are more vulnerable to virus infection (Ciencewicki et al. 2008). $\mathrm{O}_{3}$ can react with unsaturated fatty lipids in the respiratory tract to produce reactive oxygen species (ROS), such as hydrogen peroxide $\left(\mathrm{H}_{2} \mathrm{O}_{2}\right)$, lipid ozonation products, and lipid peroxides. Furthermore, oxidative stress can cause DNA damage and protein adducts, as well as apoptosis induced by mitochondrial dysfunction (Jaspers et al. 2005). The fact that the increase in $\mathrm{O}_{3}$ exposure associated with the onset of mumps might be due to immune damage. Exposure to $\mathrm{O}_{3}$ can reacts directly with unsaturated fatty lipids in the respiratory tract to produce reactive oxygen species (ROS), such as hydrogen peroxide $\left(\mathrm{H}_{2} \mathrm{O}_{2}\right)$, lipid

\section{Pollutants RR (95\% CI)}

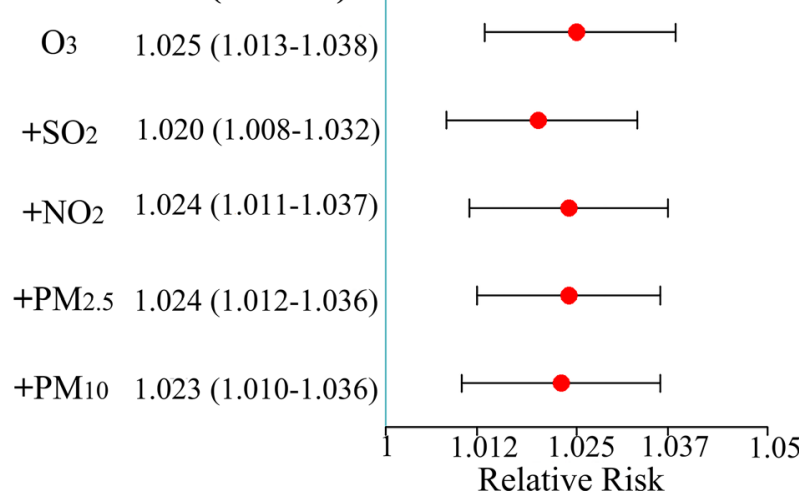

Fig. 6 Cumulative relative risk (RR) of mumps for a $10 \mu \mathrm{g} / \mathrm{m}^{3}$ increase of $\mathrm{O}_{3}$. The $\mathrm{RR}$ for " $\mathrm{O}_{3}$ " is estimated by using the one-pollutant model. The $\mathrm{RR}$ for " $+\mathrm{X}$ " (i.e., $\mathrm{SO}_{2}, \mathrm{NO}_{2}, \mathrm{PM}_{2.5}$, and $\mathrm{PM}_{10}$ ) is estimated by using the two-pollutant models (Eq. 4), i.e., the RR for $\mathrm{O}_{3}$ in the presence of a second pollutant in the model 
ozonation products, and lipid peroxides. It can cause oxidation of lipids and proteins in the lining fluid of the pulmonary airway (RTLF) (Valacchi et al. 2004), as well as damage to the nasal cavity and oral mucosa (Carson et al. 1987; Kienast et al. 1994), thereby increasing the risk of MuV and respiratory diseases. As a consequence of the human upper respiratory tract infection, the respiratory immune system suffers certain damage, and the immune function of $\mathrm{T}$ cells to $\mathrm{MuV}$ become weakened, resulting in the spread of $\mathrm{MuV}$ from the lymph nodes (Rubin et al. 2015), increasing the risk of mumps.

\section{Robustness of statistical estimates}

In the validation analysis, the model showed reasonable predictive performance. The model parameterized with the training data set decently predicted the prevalence of mumps, with the correlation coefficient of 0.87 and the root mean square error of 9.63. In the sensitivity analysis, when we changed the degrees of freedom of time per year from $7 \mathrm{df}$ to $6 \mathrm{df}$ and $8 \mathrm{df}$, the model estimates remained steady, indicating robust modeling results (Table 2).

With respect to the models used in this study, GAM has been commonly used to investigate the relationship between air pollution exposure and respiratory infectious diseases (Chen et al. 2016; Wang et al. 2020; Zhu et al. 2019), while DLNM couples the hysteresis and nonlinear relationship. When simulating the association between air pollution and respiratory infectious diseases, this modeling method shows better goodness of fitting and can simultaneously describe the hysteresis and nonlinear effects, which compensates the lack of the hysteresis model in capturing the nonlinear relationship (Braga et al. 2001; Zeng et al. 2020).

Under the current air quality guideline in China, the safe thresholds are 160 and $200 \mu \mathrm{g} / \mathrm{m}^{3}$ for the daily maximum 8hour average concentration and hourly average concentration, respectively (Ministry of Ecology and Environment of the People's Republic of China 2012). Both thresholds are higher than those recommended by the WHO. In the 14th Five-Year plan of China (2021-2025), it is proposed to curb the increasing trend of $\mathrm{O}_{3}$ through reducing the emissions of $\mathrm{NO}_{\mathrm{x}}$ and VOCs (Central People's Government of the People's Republic of China. 2021). Given the adverse health effects of $\mathrm{O}_{3}$ exposure reported in the present and previous studies (Kai et al. 2018; Niewiadomska et al. 2020), from a conservative

Table 2 Cumulative RR of mumps in different time-series in $\mathrm{O}_{3}$ exposure

\begin{tabular}{lll}
\hline $\mathrm{df}$ & Cumulative RR & $95 \% \mathrm{CI}$ \\
\hline 6 & 1.018 & $1.006-1.029$ \\
7 & 1.025 & $1.013-1.038$ \\
8 & 1.027 & $1.015-1.039$ \\
\hline
\end{tabular}

perspective, the air quality guideline in China may need to be refined for lowering health burden due to $\mathrm{O}_{3}$ exposure. An early warning system can be established to issue notifications of reducing outdoor activities in $\mathrm{O} 3$ pollution seasons.

This study has several limitations. Firstly, we used the average concentrations observed at the air quality stations in Chongqing to evaluate the exposure levels, without considering the variation personal exposure levels (Zeger et al. 2000). Most of these monitoring stations were located in the districts with high population densities, which reasonably represented the average ambient exposure levels of the local population. Nevertheless, the exposure levels of each individual might be considerably different from the average ambient exposure levels due to variation in personal daily activities and indoor-outdoor air exchange rates. The personal exposure levels could be validated and refined by using portable air quality monitors (Dessimond et al. 2021; Schmitz et al. 2019). Secondly, there existed time gaps between the onset of a patient and the patient's hospital visit. Some patients with mild symptoms might not visit hospitals, which would also introduce uncertainty to the exposure-response relationship (Chen et al. 2017; Feng et al. 2016). Finally, we were unable to collect individual information, including personal lifestyles (e.g., smoking and indoor ventilation frequency), age, and gender. For the elderly, pregnant women, and children, weaker respiratory immune systems tended to induce higher susceptibility to mumps when they were exposed to air pollution (Capraz et al. 2017; Chen et al. 2019). In future research, patients can be divided into various groups based on personal information to investigate the association between air pollution and the risk of mumps.

\section{Conclusions}

To the best of our knowledge, this is the first study of using DLNM to examine the association between $\mathrm{O}_{3}$ exposure and prevalence of mumps in a populous and humid megacity. On the basis of the DLNM results, we found that the risk of mumps was significantly positively associated with the $\mathrm{O}_{3}$ concentrations within a 7-day lag time window. The relative risk of mumps increased by $2.5 \%$ for $10 \mu \mathrm{g} / \mathrm{m}^{3}$ increase in the $\mathrm{O}_{3}$ concentrations. The results of this study advance the understanding of the impact of $\mathrm{O}_{3}$ exposure on the risk of mumps, suggesting the importance of controlling $\mathrm{O}_{3}$ pollution for protecting public health.

Abbreviations $\mathrm{O}_{3}$, Ozone; MuV, Mumps Virus; RR, Relative Risk; WHO, World Health Organization; RTLF, Respiratory Tract Lining Fluid; DLNM, Distributed Lag Non-linear Model; GAM, Generalized Additive Model; CI, Confidence Intervals; $\mathrm{SO}_{2}$, Sulfur Dioxide; $\mathrm{NO}_{2}$, Nitrogen Dioxide; CO, Carbon Monoxide; $\mathrm{PM}_{2.5}$, Fine Particulate 
Matter; $\mathrm{PM}_{10}$, Respirable Particulate Matter; VOCs, Volatile Organic Compounds; df, degrees of freedom

Supplementary Information The online version contains supplementary material available at https://doi.org/10.1007/s11356-021-15473-2.

Acknowledgements We are grateful to the National Key R\&D Program of China (2017YFC1502903), the National Natural Science Foundation of China (22076129), the Sichuan Key R\&D Project (2020YFS0055), the Chengdu Major Technology Application and Demonstration Project (2020-YF09-00031-SN), and the Fundamental Research Funds for the Central Universities (YJ201765).

Data and materials availability The datasets used in this study can be provided by contacting the corresponding author.

Author contribution WX and WZ drafted the manuscript. HZ, CS, and BW provided extensive comments on this manuscript. WX and WZ participated in the data preparation and model coding. YZ designed research plan and revised manuscript. All authors had read and approved the final manuscript.

Funding This study was supported by the National Key R\&D Program of China (2017YFC1502903), ; the National Natural Science Foundation of China (22076129), the Sichuan Key R\&D Project (2020YFS0055), the Chengdu Major Technology Application and Demonstration Project (2020-YF09-00031-SN), and the Fundamental Research Funds for the Central Universities (YJ201765).

\section{Declarations}

Ethics approval and consent to participate As the data used in the present study included no personally identifiable information, individual informed consent was waived.

Consent for publication Not applicable.

Competing interests The authors declare no competing interests.

\section{References}

Averett N (2016) Pacific Island Countries and Climate Change Examining Associated Human Health Vulnerabilities. Environ Health Perspect 124(11):A208-A208. https://doi.org/10.1289/ehp. 124-A208

Betakova T, Svetlikova D, Gocnik M (2013) Overview of measles and mumps vaccine: origin, present, and future of vaccine production. Acta Virol 57(2):91-96. https://doi.org/10.4149/av_2013_02_91

Bhaskaran K, Gasparrini A, Hajat S, Smeeth L, Armstrong B (2013) Time series regression studies in environmental epidemiology. Int J Epidemiol 42(4):1187-1195. https://doi.org/10.1093/ije/dyt092

Braga ALF, Zanobetti A, Schwartz J (2001) The time course of weatherrelated deaths. Epidemiology. 12(6):662-667. https://doi.org/10. 1097/00001648-200111000-00014

Capraz O, Deniz A, Dogan N (2017) Effects of air pollution on respiratory hospital admissions in Istanbul, Turkey, 2013 to 2015. Chemosphere. 181:544-550. https://doi.org/10.1016/j. chemosphere.2017.04.105

Carson JL, Collier AM, Hu SC, Smith CA, Stewart P (1987) The Appearance of Compound Cilia in the Nasal-Mucosa of Normal Human-Subjects Following Acute, Invivo Exposure to Sulfur-
Dioxide. Environ Res 42(1):155-165. https://doi.org/10.1016/ s0013-9351(87)80017-8

Central People's Government of the People's Republic of China (2021) The 14th Five-Year plan for national economic and social development of the people's Republic of China and the outline of long-term goals for 2035. http://www.gov.cn/xinwen/2021-03/13/content 5592681.htm. Accessed June 01, 2021

Chen C-C, Chiu H-F, Yang C-Y (2016) Air pollution exposure and daily clinical visits for allergic rhinitis in a subtropical city: Taipei, Taiwan. J Toxicol Environ Health A 79(12):494-501. https://doi. org/10.1080/15287394.2016.1182002

Chen G, Zhang W, Li S, Zhang Y, Williams G, Huxley R, Ren H, Cao W, Guo Y (2017) The impact of ambient fine particles on influenza transmission and the modification effects of temperature in China: a multi-city study. Environ Int 98:82-88. https://doi.org/10.1016/j. envint.2016.10.004

Chen CWS, Hsieh Y-H, Su H-C, Wu JJ (2018) Causality test of ambient fine particles and human influenza in Taiwan: age group-specific disparity and geographic heterogeneity. Environ Int 111:354-361. https://doi.org/10.1016/j.envint.2017.10.011

Chen ZJ, Cui LL, Cui XX, Li XW, Yu KK, Yue KS, Dai ZX, Zhou JW, Jia G, Zhang J (2019) The association between high ambient air pollution exposure and respiratory health of young children: a cross sectional study in Jinan, China. Sci Total Environ 656:740-749. https://doi.org/10.1016/j.scitotenv.2018.11.368

Ciencewicki J, Trivedi S, Kleeberger SR (2008) Oxidants and the pathogenesis of lung diseases. J Allergy Clin Immunol 122(3):456-468. https://doi.org/10.1016/j.jaci.2008.08.004

Clifford HD, Perks KL, Zosky GR (2015) Geogenic PM10 exposure exacerbates responses to influenza infection. Sci Total Environ 533:275-282. https://doi.org/10.1016/j.scitotenv.2015.07.001

CMA (2020) China Meteorology Data. http://data.cma.cn/. Accessed January 01, 2021

Cruz-Sanchez TM, Haddrell AE, Hackett TL, Singhera GK, Marchant D, Lekivetz R, Meredith A, Horne D, Knight DA, van Eeden SF, Bai TR, Hegele RG, Dorscheid DR, Agnes GR (2013) Formation of a Stable Mimic of Ambient Particulate Matter Containing Viable Infectious Respiratory Syncytial Virus and Its Dry-Deposition Directly onto Cell Cultures. Anal Chem 85(2):898-906. https:// doi.org/10.1021/ac302174y

Cui A, Zhu Z, Chen M, Zheng H, Liu L, Wang Y, Ma Y, Wang C, Fang X, Li P, Guan R, Wang S, Zhou J, Zheng L, Gao H, Ding Z, Li L, Bo F, Sun Z, Zhang Z, Feng D, He J, Chen H, Jin L, Rota PA, Xu W (2014) Epidemiologic and genetic characteristics of mumps viruses isolated in China from 1995 to 2010. Infect Genet Evol 21:384-390. https://doi.org/10.1016/j.meegid.2013.12.005

DeFelice TP (2020) Relationship between temporal anomalies in $\mathrm{PM}_{2.5}$ concentrations and reported influenza/influenza-like illness activity. Heliyon 6(8). https://doi.org/10.1016/j.heliyon.2020.e04726

Dessimond B, Annesi-Maesano I, Pepin JL, Srairi S, Pau G (2021) Academically Produced Air Pollution Sensors for Personal Exposure Assessment: The Canarin Project. Sensors. 21(5). https:// doi.org/10.3390/s21051876

van Doremalen N, Bushmaker T, Morris DH, Holbrook MG, Gamble A, Williamson BN, Tamin A, Harcourt JL, Thornburg NJ, Gerber SI, Lloyd-Smith JO, de Wit E, Munster VJ (2020) Aerosol and Surface Stability of SARS-CoV-2 as Compared with SARS-CoV-1. N Engl J Med 382(16):1564-1567. https://doi.org/10.1056/ NEJMc2004973

Feng C, Li J, Sun W, Zhang Y, Wang Q (2016) Impact of ambient fine particulate matter $\left(\mathrm{PM}_{2.5}\right)$ exposure on the risk of influenza-likeillness: a time-series analysis in Beijing, China. Environ Health 15. https://doi.org/10.1186/s12940-016-0115-2

Gasparrini A (2011) Distributed lag linear and non-linear models in R: the package dlnm. J Stat Softw 43(8):1-20. https://doi.org/10.18637/jss. v043.i08 
Gasparrini A, Armstrong B, Kenward MG (2010) Distributed lag nonlinear models. Stat Med 29(21):2224-2234. https://doi.org/10.1002/ $\operatorname{sim} .3940$

Griffin DW (2007) Atmospheric movement of microorganisms in clouds of desert dust and implications for human health. Clin Microbiol Rev 20(3):459-477. https://doi.org/10.1128/cmr.00039-06

Guo X, Song H, Liang L (2020) Spatial and Temporal Variations of Ozone Concentration in China during 2015-2017. Meteorol Environ Sci 43(3):41-50. https://doi.org/10.16765/j.cnki.16737148.2020.03.006

Hao J, Yang Z, Huan S, Yang W, Zhu Z, Tian L, Lu Y, Xiang H, Liu S (2019) The association between short-term exposure to ambient air pollution and the incidence of mumps in Wuhan, China: a timeseries study. Environ Res 177. https://doi.org/10.1016/j.envres. 2019.108660

Hess JJ, Saha S, Luber G (2014) Summertime Acute Heat Illness in U.S. Emergency Departments from 2006 through 2010: analysis of a Nationally Representative Sample. Environ Health Perspect 122(11):1209-1215. https://doi.org/10.1289/ehp.1306796

Ho YC, Su BH, Su HJ, Chang HL, Lin CY, Chen HF, Chen KT (2015) The association between the incidence of mumps and meteorological parameters in Taiwan. Hum Vaccines Immunotherapeutics 11(6):1406-1412. https://doi.org/10.1080/21645515.2015.1029687

Hu W, Li Y, Han W, Xue L, Zhang W, Ma W, Bi P (2018) Meteorological factors and the incidence of mumps in Fujian Province, China, 2005-2013: non-linear effects. Sci Total Environ 619:1286-1298. https://doi.org/10.1016/j.scitotenv.2017.11.108

Hviid A, Rubin S, Muhlemann K (2008) Mumps. Lancet 371(9616):932 944. https://doi.org/10.1016/s0140-6736(08)60419-5

Jaspers I, Ciencewicki JM, Zhang WL, Brighton LE, Carson JL, Beck MA, Madden MC (2005) Diesel exhaust enhances influenza virus infections in respiratory epithelial cells. Toxicol Sci 85(2):990 1002. https://doi.org/10.1093/toxsci/kfi141

Kai C, M F.A, Renjie C, Leiwen J, Bryan J, Alexandra S, Annette P, Jun B, Haidong K, L K.P (2018) Future ozone-related acute excess mortality under climate and population change scenarios in China: a modeling study. PLoS Med 15(7). https://oi.org/10.1371/journal. pmed. 1002598

Kienast K, Riechelmann H, Knorst M, Schlegel J, Mullerquernheim J, Schellenberg J, Ferlinz R (1994) An Experimental-Model for the Exposure of Human Ciliated Cells to Sulfur-Dioxide at Different Concentrations. Clin Investigator 72(3):215-219. https://doi.org/ 10.1007/BF00189317

Kim H, Kim H, Lee J-T (2015) Effects of ambient air particles on mortality in Seoul: have the effects changed over time? Environ Res 140:684-690. https://doi.org/10.1016/j.envres.2015.05.029

Lee YC, Chan KL, Wenig MO (2019) Springtime warming and biomass burning causing ozone episodes in South and Southwest China. Air Qual Atmos Health 12(8):919-931. https://doi.org/10.1007/s11869019-00709-5

Li RZ, Cheng SH, Luo C, Rutherford S, Cao J, Xu QQ, Liu XD, Liu YX, Xue FZ, Xu Q, Li XJ (2017) Epidemiological Characteristics and Spatial-Temporal Clusters of Mumps in Shandong Province, China, 2005-2014. Sci Rep 7. https://doi.org/10.1038/srep46328

Luo L, Zhang Y, Jiang J, Luan H, Yu C, Nan P, Luo B, You M (2018) Short-Term Effects of Ambient Air Pollution on Hospitalization for Respiratory Disease in Taiyuan, China: a Time-Series Analysis. Int J Environ Res Public Health 15(10). https://doi.org/10.3390/ ijerph 15102160

MEEC (2020) Air Quality Daily Report for China. http://datacenter.mee. gov.cn/. Accessed January 01, 2021

Meselson M (2020) Droplets and Aerosols in the Transmission of SARSCoV-2. N Engl J Med 382(21):2063-2063. https://doi.org/10.1056/ NEJMc2009324

Ministry of Ecology and Environment of the People's Republic of China (2012). Ambient Air Quality Standards. http://www.mee.gov.cn/ ywgz/fgbz/bz/bzwb/dqhjbh/dqhjzlbz/201203/t20120302_224165. htm. Accessed June 01, 2021

Modarres R, Dehkordi AK (2005) Daily air pollution time series analysis of Isfahan City. Int J Environ Sci Technol (Germany) 2(3):259-267. https://doi.org/10.1007/bf03325885

NBSC (2019) China statistical yearbook of 2019. In: National Bureau of Statistics of the People's Republic of China. http://www.stats.gov. $\mathrm{cn} / \mathrm{tj} \mathrm{jj} / \mathrm{ndsj} / 2019 /$ indexeh.htm. Accessed January 01, 2021

Nenna R, Evangelisti M, Frassanito A, Scagnolari C, Pierangeli A, Antonelli G, Nicolai A, Arima S, Moretti C, Papoff P, Villa MP, Midulla F (2017) Respiratory syncytial virus bronchiolitis, weather conditions and air pollution in an Italian urban area: an observational study. Environ Res 158:188-193. https://doi.org/10.1016/j.envres. 2017.06.014

Niewiadomska E, Kowalska M, Niewiadomski A, Skrzypek M, Kowalski MA (2020) Assessment of Risk Hospitalization due to Acute Respiratory Incidents Related to Ozone Exposure in Silesian Voivodeship (Poland). Int J Environ Res Public Health 17(10). https://doi.org/10.3390/ijerph17103591

Onozuka D, Hashizume M (2011) Effect of weather variability on the incidence of mumps in children: a time-series analysis. Epidemiol Infect 139(11):1692-1700. https://doi.org/10.1017/ s0950268810002967

Peng RD, Dominici F, Louis TA (2006) Model choice in time series studies of air pollution and mortality. J R Stat Soc Series A-Stat Soc 169:179-198. https://doi.org/10.1111/j.1467-985X.2006. 00410.x

Qing C, Shu L, Zongjiao C, Biao Z, Hehua Z (2020) Association between air pollutants and outpatient and emergency hospital visits for childhood asthma in Shenyang city of China. Int J Biometeorol. https:// doi.org/10.1007/s00484-020-01934-9

Qiu H, Zhu X, Wang L, Pan J, Pu X, Zeng X, Zhang L, Peng Z, Zhou L (2019) Attributable risk of hospital admissions for overall and specific mental disorders due to particulate matter pollution: a timeseries study in Chengdu, China. Environ Res 170:230-237. https:// doi.org/10.1016/j.envres.2018.12.019

Rubin S, Eckhaus M, Rennick LJ, Bamford CGG, Duprex WP (2015) Molecular biology, pathogenesis and pathology of mumps virus. J Pathol 235(2):242-252. https://doi.org/10.1002/path.4445

Rubin S, Kennedy R, Poland G (2016) Emerging Mumps Infection. Pediatr Infect Dis J 35(7):799-801. https://doi.org/10.1097/inf. 0000000000001182

Samoli E, Stafoggia M, Rodopoulou S, Ostro B, Declercq C, Alessandrini E, Diaz J, Karanasiou A, Kelessis AG, Le Tertre A, Pandolfi P, Randi G, Scarinzi C, Zauli-Sajani S, Katsouyanni K, Forastiere F, Grp M-PS (2013) Associations between Fine and Coarse Particles and Mortality in Mediterranean Cities: results from the MED-PARTICLES Project. Environ Health Perspect 121(8): 932-938. https://doi.org/10.1289/ehp.1206124

Schmitz O, Beelen R, Strak M, Hoek G, Soenario I, Brunekreef B, Vaartjes I, Dijst MJ, Grobbee DE, Karssenberg D (2019) Data Descriptor: high resolution annual average air pollution concentration maps for the Netherlands. Sci Data 6. https://doi.org/10.1038/ sdata.2019.35

Stekhoven DJ, Buehlmann P (2012) MissForest-non-parametric missing value imputation for mixed-type data. Bioinformatics. 28(1):112118. https://doi.org/10.1093/bioinformatics/btr597

Su R, Lu KD, Yu JY, Tan ZF, Jiang MQ, Li J, Xie SD, Wu YS, Zeng LM, Zhai CZ, Zhang YH (2018) Exploration of the formation mechanism and source attribution of ambient ozone in Chongqing with an observation-based model. Sci China-Earth Sci 61(1):23-32. https:// doi.org/10.1007/s1 1430-017-9104-9

R Development Core Team (2012) R: A language and environment for statistical computing. R Foundation for Statistical Computing, Vienna, Austria. ;https://www.R-project.org/. Accessed 01 Jan ;2021 
Thurston GD, Kipen H, Annesi-Maesano I, Balmes J, Brook RD, Cromar K, De Matteis S, Forastiere F, Forsberg B, Frampton MW, Grigg J, Heederik D, Kelly FJ, Kuenzli N, Laumbach R, Peters A, Rajagopalan ST, Rich D, Ritz B, Samet JM, Sandstrom T, Sigsgaard T, Sunyer J, Brunekreef B (2017) A joint ERS/ATS policy statement: what constitutes an adverse health effect of air pollution? An analytical framework. Eur Respir J 49(1). https://doi.org/ 10.1183/13993003.00419-2016

Valacchi G, Pagnin E, Corbacho AM, Olano E, Davis PA, Packer L, Cross CE (2004) In vivo ozone exposure induces antioxidant/ stress-related responses in murine lung and skin. Free Radic Biol Med 36(5):673-681. https://doi.org/10.1016/j.freeradbiomed.2003. 12.005

Wang M, Wang S, Wang X, Tian Y, Wu Y, Cao Y, Song J, Wu T, Hu Y (2020) The association between $\mathrm{PM}_{2.5}$ exposure and daily outpatient visits for allergic rhinitis: evidence from a seriously air-polluted environment. Int J Biometeorol 64(1):139-144. https://doi.org/10. 1007/s00484-019-01804-Z

WHO (2016) Ambient Air Pollution: a Global Assessment of Exposure and Burden of Disease. https://www.who.int/phe/publications/airpollution-global-assessment/en/. Accessed January 01, 2021

WHO (2020) Mumps-Reported cases by country https://apps.who.int/ gho/data/view.main.1540 53?lang=en. Accessed January 01, 2021

Wood SN (2011) Fast stable restricted maximum likelihood and marginal likelihood estimation of semiparametric generalized linear models. J R Stat Soc B 73(1):3-36. https://doi.org/10.1111/j.1467-9868.2010. 00749.x

Yan ML, Liu ZR, Liu XT, Duan HY, Li TT (2013) Meta-analysis of the Chinese studies of the association between ambient ozone and mortality. Chemosphere. 93(6):899-905. https://doi.org/10.1016/j. chemosphere.2013.05.040
Young PC, Minchin PEH (1991) Environmentric Time-Series AnalysisModeling Natural Systems from Experimental Time-Series Data. Int J Biol Macromol 13(3):190-201. https://doi.org/10.1016/01418130(91)90046-w

Zeger SL, Thomas D, Dominici F, Samet JM, Schwartz J, Dockery D, Cohen A (2000) Exposure measurement error in time-series studies of air pollution: concepts and consequences. Environ Health Perspect 108(5):419-426. https://doi.org/10.2307/3454382

Zeng W, Zhao H, Liu R, Yan W, Qiu Y, Yang F, Shu C, Zhan Y (2020) Association between $\mathrm{NO}_{2}$ cumulative exposure and influenza prevalence in mountainous regions: a case study from southwest China. Environ Res 189. https://doi.org/10.1016/j.envres.2020.109926

Zha WT, Li WT, Zhou N, Zhu JJ, Feng RH, Li T, Du YB, Liu Y, Hong XQ, Lv Y (2020) Effects of meteorological factors on the incidence of mumps and models for prediction, China. BMC Infect Dis 20(1): 11. https://doi.org/10.1186/s12879-020-05180-7

Zhang XG, Fung JCH, Lau AKH, Hossain MS, Louie PKK, Huang W (2021) Air quality and synergistic health effects of ozone and nitrogen oxides in response to China's integrated air quality control policies during 2015-2019. Chemosphere. 268. https://doi.org/10.1016/ j.chemosphere.2020.129385

Zhu X, Qiu H, Wang L, Duan Z, Yu H, Deng R, Zhang Y, Zhou L (2019) Risks of hospital admissions from a spectrum of causes associated with particulate matter pollution. Sci Total Environ 656:90-100. https://doi.org/10.1016/j.scitotenv.2018.11.240

Publisher's note Springer Nature remains neutral with regard to jurisdictional claims in published maps and institutional affiliations. 